\title{
Antioxidant and immunomodulatory properties of polysaccharides from Allanblackia floribunda Oliv stem bark and Chromolaena odorata (L.) King and H.E. Robins leaves
}

Thaddée Boudjeko ${ }^{1,2^{*}}$, Rosette Megnekou ${ }^{3}$, Alice Louise Woguia ${ }^{2}$, Francine Mediesse Kegne ${ }^{1,2}$, Judith Emery Kanemoto Ngomoyogoli ${ }^{1,2}$, Christiane Danielle Nounga Tchapoum ${ }^{1,2}$ and Olga Koum ${ }^{1,3}$

\begin{abstract}
Background: Many plant polysaccharides have shown high antioxidant and immunostimulating properties and can be explored as novel molecules with biological properties that can potentially improve immune function. The objective of this work was to characterize soluble and cell wall polysaccharides isolated from the stem bark of Allanblackia floribunda and Chromolaena odorata leaves and to evaluate their antioxidant and immunomodulatory properties.

Methods: Three polysaccharide fractions: soluble polysaccharides (PoS), pectins (Pec) and hemicelluloses (Hem) were extracted from A. floribunda stem bark and C. odorata leaves. These samples were analysed for their proteins, phenolic compounds and total sugar contents. The monosaccharide composition was determined by gas chromatography and arabinogalactan proteins content in PoS was evaluated by rocket electrophoresis. The in vitro antioxidant activities were evaluated by 1, 1-diphenyl-2-picryl hydrazyl (DPPH) and 2,2'-azino-bis-3-éthylbenzylthiazoline6 -sulphonic acid (ABTS) radical scavenging assays and ferrous ions chelating activity. Immunomodulatory activities were performed on the peripheral blood mononuclear cells (PBMCs) using proliferation and enzyme linked immunospot (ELISPOT) method to determine the production of an interferon-gamma.

Results: The characterization of the various fractions showed varied metabolites in each plant. In PoS fractions, Ara and Gal were the major monosaccharides found, indicating that arabinogalactans are the primary macromolecules. Hem fractions contained predominantly Xyl and GalA for A. floribunda and Xyl (upto $80 \%$ ) for and C. odorata. A. floribunda Hem fraction and C. odorata PoS fraction showed significant DPPH and ABTS radical scavenging activities and immunostimulatory activity via stimulation of PBMC and production of IFN- $\gamma$ in a dose-dependent manner.
\end{abstract}

Conclusion: The results obtained from this study support the ethnomedicinal use of the stem bark of $A$. floribunda and leaves of $C$. odorata. Further research is necessary to have supporting evidence that the antioxidative and immunomodulative activities of these fractions are really connected to the polysaccharides and not polyphenols.

Keywords: Allanblackia floribunda, Chromolaena odorata, Polysaccharides, Antioxidant activities, Immunomodulatory activities

\footnotetext{
*Correspondence: boudjeko@yahoo.com

${ }^{1}$ Laboratory of Phytoprotection and Valorisation of Plants Resources,

Biotechnology Centre-Nkolbisson, P.O. Box 3851, Messa, Yaounde,

Cameroon

Full list of author information is available at the end of the article
} 


\section{Background}

Polysaccharides are natural macromolecules consisting of multiple monosaccharides units. They represent a structurally diverse class of macromolecules that are widely distributed in nature and play an important role in controlling cell division, regulating cell growth and maintaining normal metabolism of living organisms. Polysaccharides of higher plants are a potential source of pharmacologically active compounds. Numerous studies have shown that polysaccharides isolated from medicinal plants could affect the immune responses both in vivo and in vitro and have the potential of being immunomodulators [1]. For example, polysaccharides such as lentinan, schizophyllan, and krestin have been used in clinical cancer therapies [2]. The biological activities of polysaccharides include antiviral, antitumor, immunostimulating, anti-inflammatory, anticomplementary, anticoagulant, hypoglycaemic, anti-mutagenic, anticancer, antioxidant and antitussive effects [2-4]. The discovery and evaluation of novel and safe polysaccharides from plants has become a popular research topic to detect functional foods or an alternative for the treatment of many diseases such as malaria, atherosclerosis and cancer inflammation, hypertension, wounds, scabies, rashes, abscesses, diseases associated with cellular degeneration and healing defects [4]. These various pathologies are generally evaluated in the cell through oxidative stress and inadequate immune response.

The phenomenon of oxidative stress is a state of imbalance between oxidized cellular components and antioxidants in favour of the oxidized components that can have serious consequences such as cancer and metabolic diseases. It has been shown that the parietal polysaccharides of some plants may have antioxidant activities; these include free radical scavengers [5], metal chelators [6], inhibitors of lipid peroxidation [7], reduction of DNA damage induced by $\mathrm{H}_{2} \mathrm{O}_{2} / \mathrm{FeCl}_{2}$ [8]. In addition, they exhibit hypoglycemic, hypolipidemic, immunomodulatory effects, stimulate macrophages and complement activities $[9,10]$ and increase the proliferation of lymphocytes [11].

Allanblackia floribunda Oliv (Clusiaceae) stem bark decoction is effective for the treatment of diseases such as hypertension, sexual weakness, and dysentery in the Centre and South Regions of Cameroon. Several studies on the aqueous extracts of the stem bark of A. floribunda showed that they have hypotensive activity in rats [12]. The oilseed cake improved the lipid profile on albino rats placed on a high fat diet [13]. Phytochemical data have reported the isolation of several molecules of the stem bark of $A$. floribunda (benzophenon, xanthons and biflavonoïds) [14]. These compounds have shown biological activities like cytotoxicity against cancerous cells, antiinflammatory and antimicrobial effects [15].
Chromolaena odorata (L.) King and H.E. Robins. (Asteraceae) is a herbaceous plant with fast growth, native to South America. In folk medicine, the fresh leaves are used as cataplasms after wounds, burns and to stop bleeding. Its decoction is used to treat diarrhea, malaria and diabetes. Studies have shown that the leaves of Chromolaena odorata are rich in sterols, polyterpenes, polyphenols, flavonoids, alkaloids, tannins and saponins [16]. The ethanolic extract of Chromolaena odorata leaves has cytotoxic effect, anti-inflammatory and analgesic properties $[16,17]$. Very little information is available on the antioxidant and immunomodulatory activities of the polysaccharides of A. floribunda and C. odorata.

Since decoction in water is the most common method of preparation and the most common routes of administration are oral and local application, we hypothesized that polysaccharides extracted from A. floribunda and C. odorata could have immunomodulatory properties and contribute to the therapeutic effects of extracts from these plants. This work is therefore to examine the total phenolic, protein, sugar and arabinogalactans proteins (AGPs) contents of soluble polysaccharides, pectic (Pec) and hemicellulosic (Hem) fractions of the stem bark of A. floribunda and leaves of C. odorata and to assess the antioxidant and immunomodulatory activities of these polysaccharides.

\section{Materials}

Plant material and preliminary treatment

Allanblackia floribunda stem bark (25633/SRF Cam) and C. odorata $\left(\mathrm{n}^{\circ}\right.$ 64190/SRF Cam) leaves were collected from the Centre region of Cameroon and identified at by the Cameroon National Herbarium. The plant material was chopped into small pieces and air-dried.

\section{Methods}

\section{Extraction of soluble polysaccharides}

Soluble polysaccharides (PoS) were extracted according to Schultz et al. [18]. $25 \mathrm{~g}$ of stem bark were ground into powder, put in $200 \mathrm{~mL}$ of distilled water and stirred overnight. The mixture was centrifuged at $4000 \mathrm{~g}$ for $15 \mathrm{~min}$. The supernatant was mixed with in four volumes of $95 \%$ ethanol and kept at $4{ }^{\circ} \mathrm{C}$. After $24 \mathrm{~h}$, the precipitate was centrifuged at $4000 \mathrm{~g}$ for $15 \mathrm{~min}$. The residue collected was mixed with $5 \mathrm{~mL}$ of Tris-HCl buffer $50 \mathrm{mM}$, pH 8.0. The mixture was then dialyzed and freeze-dried.

\section{Extraction of cell wall polysaccharides}

The wall was extracted according to the modified method of Ray et al. [19]. $5 \mathrm{~g}$ of plant powder were boiled in $100 \mathrm{~mL}$ of $85 \%$ ethanol for $30 \mathrm{~min}$. The mixture was centrifuged at $5000 \mathrm{~g}$ for $15 \mathrm{~min}$ and the residue introduced into $100 \mathrm{~mL}$ of $90 \%$ dimethyl sulfoxide and homogenized for $24 \mathrm{~h}$ at 
room temperature. After centrifugation under the same conditions, the residue was mixed with $100 \mathrm{~mL}$ of methanol and homogenized again for $24 \mathrm{~h}$ at room temperature. The mixture was centrifuged ( $5000 \mathrm{~g}$ for $15 \mathrm{~min}$ ), washed with acetone and the residue was dried at $45^{\circ} \mathrm{C}$.

To extract the pectic and hemicellulosic fractions, cell wall material (CWM) (1 g) was extracted twice with boiled ammonium oxalate at $0.5 \%$ for $1 \mathrm{~h}$, followed by incubation of the residue in $1 \mathrm{M} \mathrm{KOH}$ overnight at room temperature as described by Ray et al. [19]. All extracts were centrifuged and dialyzed against water. Alkaline extracts were acidified to $\mathrm{pH} 5$ with acetic acid prior to dialysis. Each fraction extracted was gravimetrically analyzed.

\section{Quantification of proteins}

Proteins were quantified using the Bradford [20] method. To each $1000 \mu \mathrm{L}$ of polysaccharide extract was added $1 \mathrm{~mL}$ of Bradford reagent. The absorbance was measured at $595 \mathrm{~nm}$ using a UV-VIS 1605 Shimadzu spectrophotometer. BSA was used as the standard.

\section{Quantification of phenolic compounds}

Phenolic compounds were estimated by using the Folin-Ciocalteu method [21]. $750 \mu \mathrm{L}$ of extract solution $(0.3 \mathrm{mg} / \mathrm{mL})$ of soluble polysaccharides, pectin and hemicelluloses were added to $75 \mu \mathrm{L}$ of Folin-Ciocalteu reagent. After $3 \mathrm{~min}, 750 \mu \mathrm{L}$ of $\mathrm{Na}_{2} \mathrm{CO}_{3}(20 \%)$ were added. The absorbance was measured at $760 \mathrm{~nm}$ using a UV-VIS 1605 Shimadzu spectrophotometer after $30 \mathrm{~min}$ in the dark. Phenolic compounds were calculated using ferulic acid as standard.

\section{Quantification of total sugars}

The determination of the total amount of sugar was done according to the method of Dubois et al. [22] where the neutral monosaccharides were heated in acid medium and were transformed to dehydrated derivatives of furfural. Practically, $0.2 \mathrm{~mL}$ of sample was mixed with $0.2 \mathrm{~mL}$ of $5 \%$ phenol. $1 \mathrm{~mL}$ of concentrated sulfuric acid was added quickly and stirred. The mixture was placed at $100{ }^{\circ} \mathrm{C}$ for 10 min during which it developed a yellow colour. The absorbance was read at $485 \mathrm{~nm}$. The amount of sugar present and their levels were calculated using glucose as standard and expressed as $\mu$ g equivalent of glucose per mg of dry polysaccharides.

\section{Analysis of monosaccharide composition}

The monosaccharide composition of soluble polysaccharides, pectic and hemicellulosic fractions was determined as previously described by Ray et al. [19]. Neutral glycosyl composition was determined by gas chromatography of their alditol acetate and their trimethyl-silyl-glycosides derivatives respectively [23].

\section{Quantification of AGPs}

AGPs quantification was done by glucosyl Yariv reagent binding in rocket gel electrophoresis. Briefly, electrophoresis was performed in $1 \%$ agarose gel containing $15 \mu \mathrm{M}$ Yariv reagent for AGP precipitation as described by Boudjeko et al. [24] in Tris-glycine buffer (25 mM Tris, $200 \mathrm{mM}$ glycine, $\mathrm{pH}$ 8.4) for several hours, until the rockets were well developed. Known volume of PoS of $A$. floribunda, PoS of $C$. odorata and $7 \mu \mathrm{L}$ of standard solution (AGP of gum arabic) $(1 \mathrm{mg} / \mathrm{mL})$ were deposited in each well. The concentration of AGP in the samples was estimated in relation to the peak area of gum arabic.

\section{1,1-diphenyl-2-picryl hydrazyl (DPPH) free-radical-scavenging assay}

The free radical scavenging activity of the polysaccharide fractions was measured in terms of their hydrogen donating or radical scavenging ability using the DPPH radical [8]. For the assay, $4000 \mu \mathrm{L}$ of the fraction at different concentrations [50-600 $\mu \mathrm{g} / \mathrm{mL}$ ] were introduce into test tubes and $1000 \mu \mathrm{L}$ of the freshly prepared solution of $400 \mu \mathrm{M} \mathrm{DPPH}$ in methanol were added. The mixture was stirred and left in the dark at $37{ }^{\circ} \mathrm{C}$ for $30 \mathrm{~min}$. The absorbance was measured at $517 \mathrm{~nm}$ using a UV-VIS 1605 Shimadzu spectrophotometer. Ascorbic acid (Asc) and Catechin (Cat) were used as the positive control.

\section{Acide 2,2'-azino-bis-3-éthylbenzylthiazoline-6-} sulphonique (ABTS) free-radical-scavenging assay

The method described by Re et al. [25] was adopted. To each $20 \mu \mathrm{L}$ of different extracts $(0.5,1,2,3$ and $4 \mathrm{mg} /$ $\mathrm{mL}$ ) concentration was added $1 \mathrm{~mL}$ of ABTS reagent. The mixture was agitated and kept in the dark for $30 \mathrm{~min}$. The absorbance was measured at $734 \mathrm{~nm}$ using UV-VIS 1605 Shimadzu spectrophotometer. Cat was used as the positive control.

\section{Chelating capability for ferrous ions}

The method of Dinis et al. [26] was used to determine the ferrous ion chelating ability. $1000 \mu \mathrm{L}$ of different extracts $[100-500 \mu \mathrm{g} / \mathrm{mL}$ ] were mixed with $100 \mu \mathrm{L}$ of $\mathrm{FeCl}_{2}(2 \mathrm{mM})$ and left in the dark for $1 \mathrm{~min}$. The mixture was added to $200 \mu \mathrm{L}$ of ferrozine $(5 \mathrm{mM})$. After $10 \mathrm{~min}$ at room temperature, the absorbance of the mixture was read at $562 \mathrm{~nm}$ against a blank (distilled water) using a UV-VIS 1605 Shimadzu spectrophotometer. EDTA was used as the positive control.

\section{Immunomodulatory activity of polysaccharide fractions Preparation of human peripheral blood mononuclear cells (PBMCs)}

Authorization for the use of human blood in this study was obtained from the Institutional Review Board of the 
Biotechnology Centre (University of Yaounde 1, Cameroon). Signed informed written consent was obtained from each enrolled person. The blood was collected from men and women between 23 and 35 years and diluted with $10 \mathrm{~mL}$ of incomplete Roswell Park Memorial Institute (RPMI-1640) medium. $15 \mathrm{~mL}$ of this mixture was added to Ficollin 2/3-1/3 (v/v) and centrifuged at 10,000g for $25 \mathrm{~min}$. PBMCs suspended in $4 \mathrm{~mL}$ of incomplete RPMI 1640 medium was washed and centrifuged at 8000g. After separation, PBMCs was finally diluted in complete RPMI 1640 medium containing type $A B$ human serum, Hepes, $200 \mathrm{mM}$ L-glutamine and $50 \mathrm{mg} / \mathrm{mL}$ Gentamicin [27] and counted with lazarrus.

\section{Cell proliferation measurement and INF- $\gamma$ production by enzyme linked immunospot technique (ELISPOT)}

The assays were carried out according to the procedures in the ELISPOT kit manual. The INF- $\gamma$ produced by PBMCs sensitizes on coat plate to form an immunocomplex. This immunocomplex was revealed by an insoluble chromogene subtrate, in which the precipitation localized generate ruddy stain [28]. The human PBMCs culture was incubated for $16 \mathrm{~h}$ at $37{ }^{\circ} \mathrm{C}$ with $5 \% \mathrm{CO}_{2}$ at $90 \%$ $\mathrm{RH}$ with different polysaccharide-enriched fractions at $100 \mu \mathrm{g} / \mathrm{mL}$ and $200 \mu \mathrm{g} / \mathrm{mL}$ and subjected to test the production of INF- $\gamma$ cytokine.

\section{Statistical analysis}

Results were expressed as mean \pm SD of three parallel measurements; ANOVA followed by the Dunett test was used to test the significant difference using GraphPad Instat 3.05 software. The level of significance was set at $p<0.05$ and the graphical representations were designed using Microsoft Excel 2007.

\section{Results}

Yield of polysaccharide fractions, total protein and phenolic compound levels

Gravimetric analysis of lyophilized fractions after sequential fractionation (Table 1) yielded significant differences between $A$. floribunda stem bark and $C$. odorata

Table 1 Yield of lyophilized polysaccharide fractions isolated from A. floribunda and C. odorata

\begin{tabular}{lcr}
\hline Fractions & A. floribunda & C. odorata \\
\hline Water-soluble fractions & $1.9 \pm 0.04$ & $2.95 \pm 0.07$ \\
Cell wall material & $40.65 \pm 3.2$ & $34.00 \pm 2.8$ \\
Ammonium oxalate fraction & $5.5 \pm 0.8$ & $2.36 \pm 0.6$ \\
KOH 1 M fraction & $2.5 \pm 0.2$ & $7.55 \pm 0.5$ \\
\hline
\end{tabular}

leaves in water-soluble fractions, ammonium oxalate fractions and $1 \mathrm{M} \mathrm{KOH}$ fractions. Water extracted more material (water-soluble-polysaccharides fractions) from C. odorata (2.95\% Dry weight (Dw)) than A. floribunda $(1.9 \% \mathrm{Dw})$ sample. On the other hand, ammonium oxalate extracted more material in A. floribunda (5.5\% of CWM) than in C. odorata (2.36 \% of CWM) (Table 1$)$. The partial characterization of total protein and phenolic contents showed that all fractions were mostly a complex of proteins (Fig. 1) and phenolic compounds (Fig. 2). Quantification of proteins content in polysaccharide fractions showed that PoS of C. odorata and Pec of A. floribunda present the higher content with $7.56 \pm 0.03$ and $8.32 \pm 0.14 \mu \mathrm{g}$ BSA equivalent respectively (Fig. 1). For the phenolic compounds, their content were higher in the Hem fraction $(151.95 \pm 14.42 \mu \mathrm{g}$ equivalent of ferulic acid/mg Dw) of $A$. floribunda and in the PoS fraction (241.04 $\pm 20.78 \mu$ g equivalent of ferulic acid/mg Dw) of C. odorata (Fig. 2).
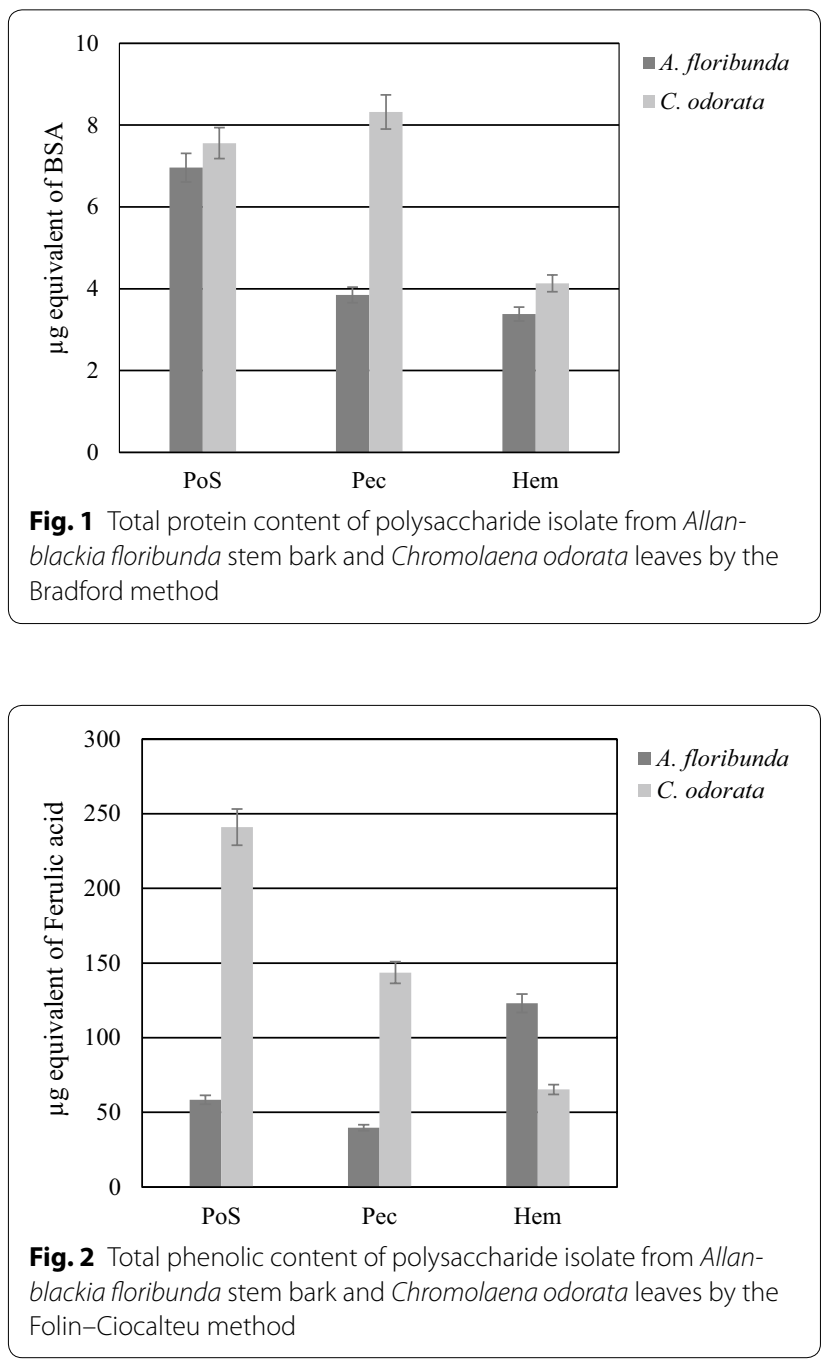


\section{Total sugar content, AGPs content and monosaccharide composition}

In the water-soluble fractions, the sugar content estimated by the phenol-sulfuric acid method [23], was much lower in A. floribunda than in C. odorata (Fig. 3). This low levels of total sugar content in water-soluble fraction suggested that this fraction could be richer in water-soluble proteins or in glycoproteins such as AGPs. The stem bark of A. floribunda had 147.54 \pm 4.38 and $151.95 \pm 1.97 \mu \mathrm{g} / \mathrm{mg}$ of dry polysaccharides for Pec and Hem respectively, while Pec and Hem of C. odorata leaves contained $561.17 \pm 23.15$ and $238.12 \pm 20.5 \mu \mathrm{g} /$ mg of dry polysaccharides respectively (Fig. 3). The total AGPs estimated by rocket electrophoresis on agarose gel showed that PoS of A. floribunda stem bark contained approximately $200.7 \mu \mathrm{g} / \mathrm{g}$ of Dw. While, PoS of C. odorata contained approximately $25.3 \mu \mathrm{g} / \mathrm{g}$ of Dw (Fig. 4).

The monosaccharide composition is shown on Fig. 5. In A. floribunda (Fig. 5a), the PoS is mainly composed of Ara (27 \%) and Gal (19.3\%). The high level of Xyl (30.7 \%) and Ara (14.6\%), in the Hem of A. floribunda, suggests the presence of arabinoxylan type hemicellulose. Pec contained more than $50 \%$ of GalA (Fig. 5a). In C. odorata leaves, PoS was mainly composed of Gal (23.4\%), Ara (18.9\%) and GalA (15.3\%); Pec was rich in GalA (55.5\%), Ara (13.2 \%) and Glu (12.8\%) and Hem mainly contained Xyl (85.8 \%) (Fig. 5b).

\section{DPPH and ABTS radical scavenging activities}

The DPPH free radical, a stable radical with purple color with a maximum absorption at $517 \mathrm{~nm}$, has been widely used as a tool to evaluate the free radical scavenging activities of antioxidants $[8,13]$. When DPPH encounters antioxidant scavengers, its purple colour rapidly fades because it is changed to the non-radical form DPPH-H. On the basis of this principle, the scavenging effects of the polysaccharide fractions on the $\mathrm{DPPH}$ radical were measured and the results are shown in

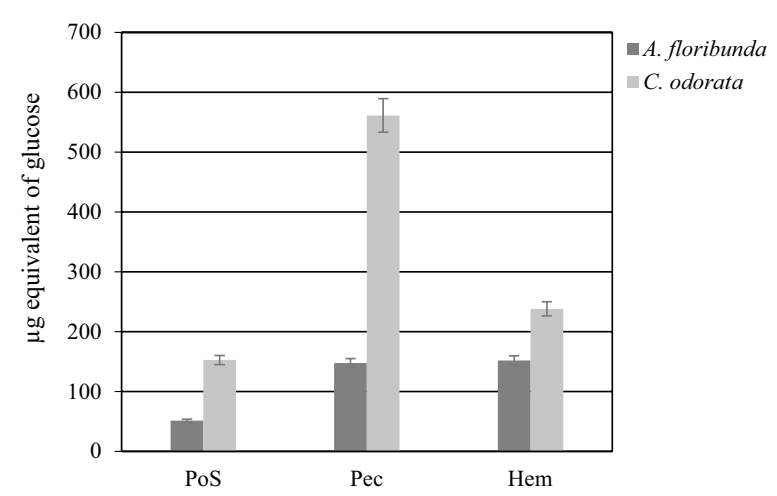

Fig. 3 Total sugar content of polysaccharide isolate from Allanblackia floribunda stem bark and Chromolaena odorata leaves by the phenol-sulfuric acid method

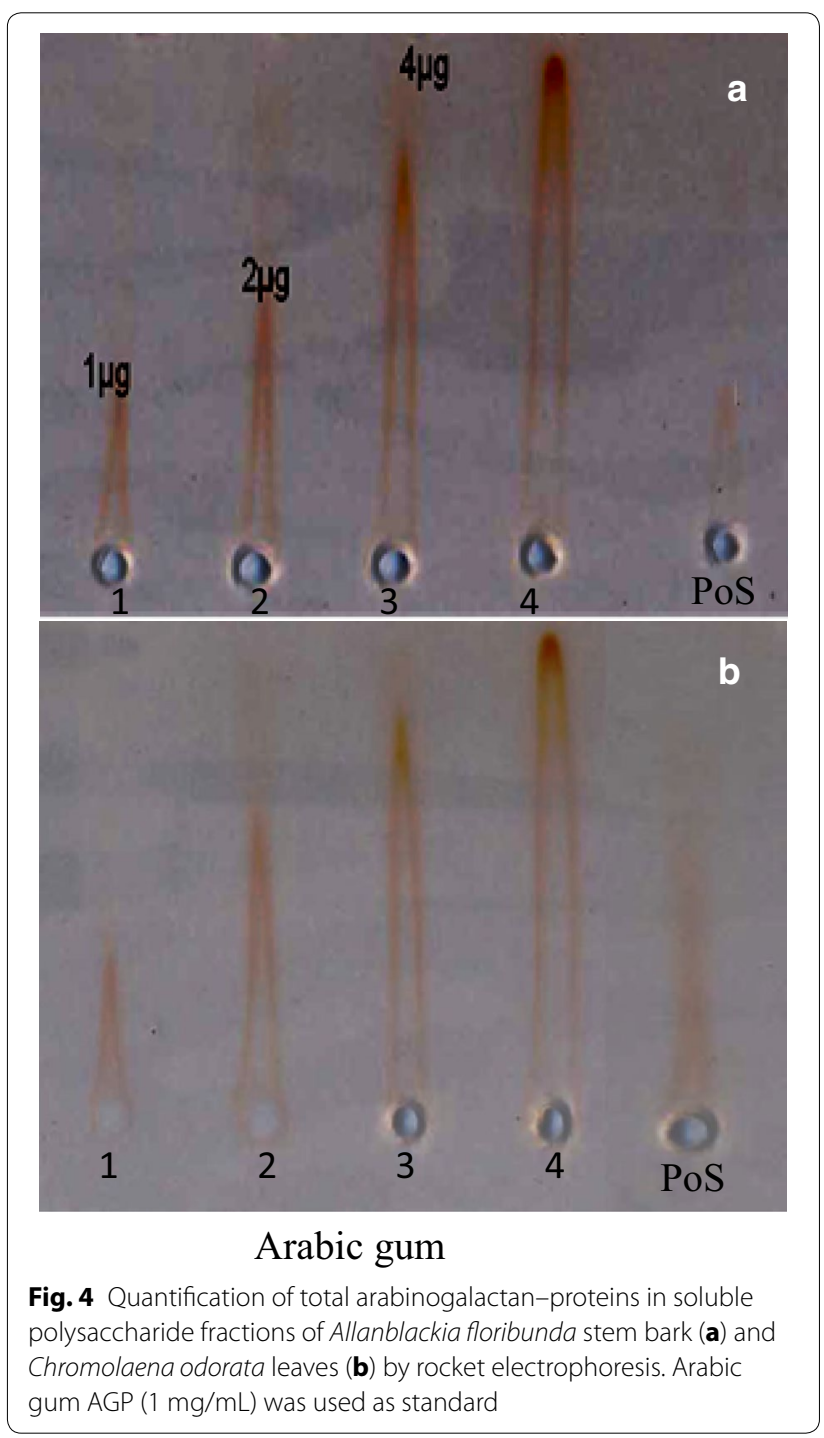

Fig. 6. The scavenging activities of polysaccharides fractions increased significantly with the increase in sample concentration ranging from 50 to $300 \mu \mathrm{g} / \mathrm{mL}$ for A. floribunda and 100 to $600 \mu \mathrm{g} / \mathrm{mL}$ for C. odorata. In relation to the DPPH inhibition, Hem of $A$. floribunda presented the best activity with $61.84 \pm 1.3 \%$ at $300 \mu \mathrm{g} / \mathrm{mL}$ (Fig. 6a). For C. odorata polysaccharide fractions, at the concentration of $300 \mu \mathrm{g} / \mathrm{mL}$, the scavenging activities were 27.70, 59.91 and $23.20 \%$ for PoS, Pec and Hem respectively (Fig. 6b). The same observations were made with ABTS radical scavenging activity, where $\operatorname{Hem} A$. floribunda presented the best activity with $70.01 \pm 0.16 \%$ at $4 \mathrm{mg} / \mathrm{mL}$ (Fig. 7a). However, for $C$. odorata, the best activity was obtained with $\operatorname{PoS}(91.91 \pm 0.9 \%$ at $4 \mathrm{mg} / \mathrm{mL})$ (Fig. 7b).

\section{Ferrous ion chelating ability}

Metal chelating capacity is important in reducing the concentration of transition metals that may act as catalysts to 


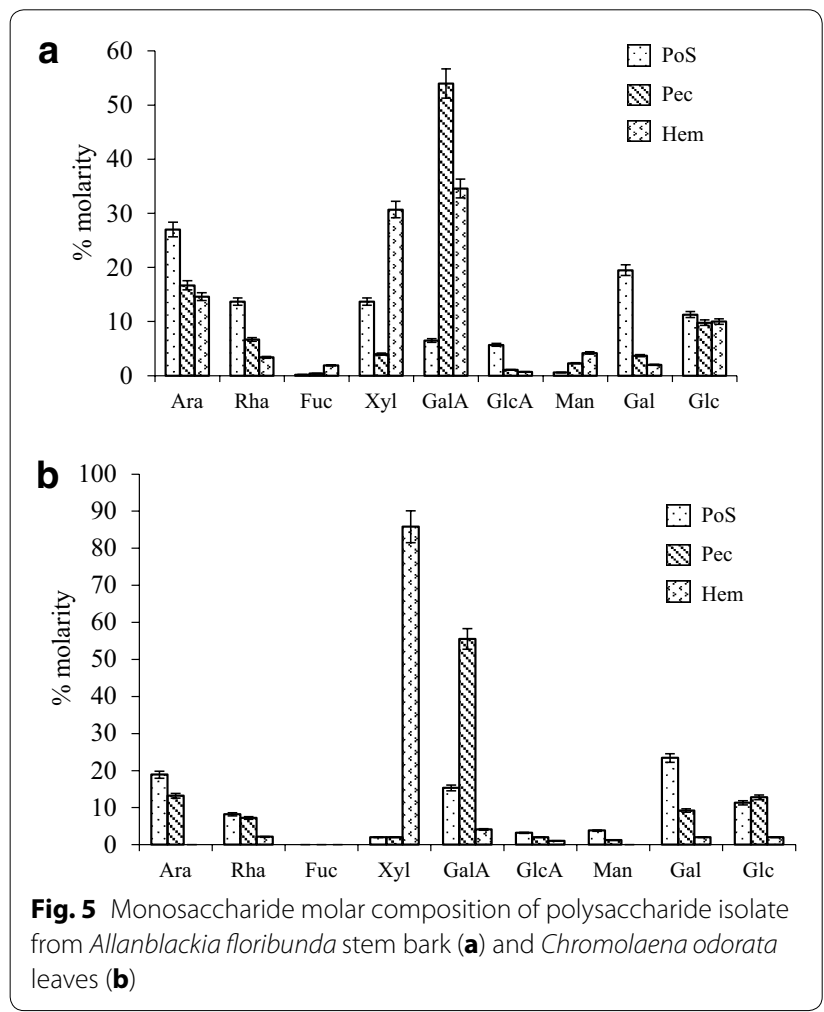

generate the first few radicals and initiate the radical-mediated oxidative chain reactions in biological systems. Ionchelating agents may also inhibit the Fenton reaction and hydroperoxide decomposition. $\mathrm{Fe}^{2+}$ ion is the most powerful pro-oxidant able to form complexes with ferrozine. Earlier reports have revealed that $\mathrm{Fe}^{2+}$ accelerates lipid peroxidation by breaking down hydrogen and lipid peroxides formed by the Fenton free radical reaction. The chelating effect on ferrous ions is therefore a widely used method to evaluate antioxidant activity. The chelating ability of polysaccharide fractions are presented in Fig. 8. At the concentration of 100 to $500 \mu \mathrm{g} / \mathrm{mL}$, PoS of A. floribunda presented the best activity (54.25 \pm 4.07 to $78.91 \pm 1 \%$ (Fig. $8 \mathrm{a}$ ). Pec of A. floribunda and the three fractions of C. odorata, showed poor ferrous ion chelating ability (Fig. 8a, b).

\section{Immunomodulatory activities of polysaccharide fractions}

The evaluation of cell proliferation and interferon production by ELISPOT in the presence of one mitogen (PHA) and two positive controls [BCG and malaria antigen (Mal $\mathrm{Ag})$ ] showed that PBMCs produced more interferon in the presence of mitogen and the two positive controls than in the negative control (Fig. 9). The ELISPOT test in the presence of the three polysaccharide fractions showed that not all extracts had an immunostimulatory capacity. In fact, PoS and Pec of A. floribunda showed

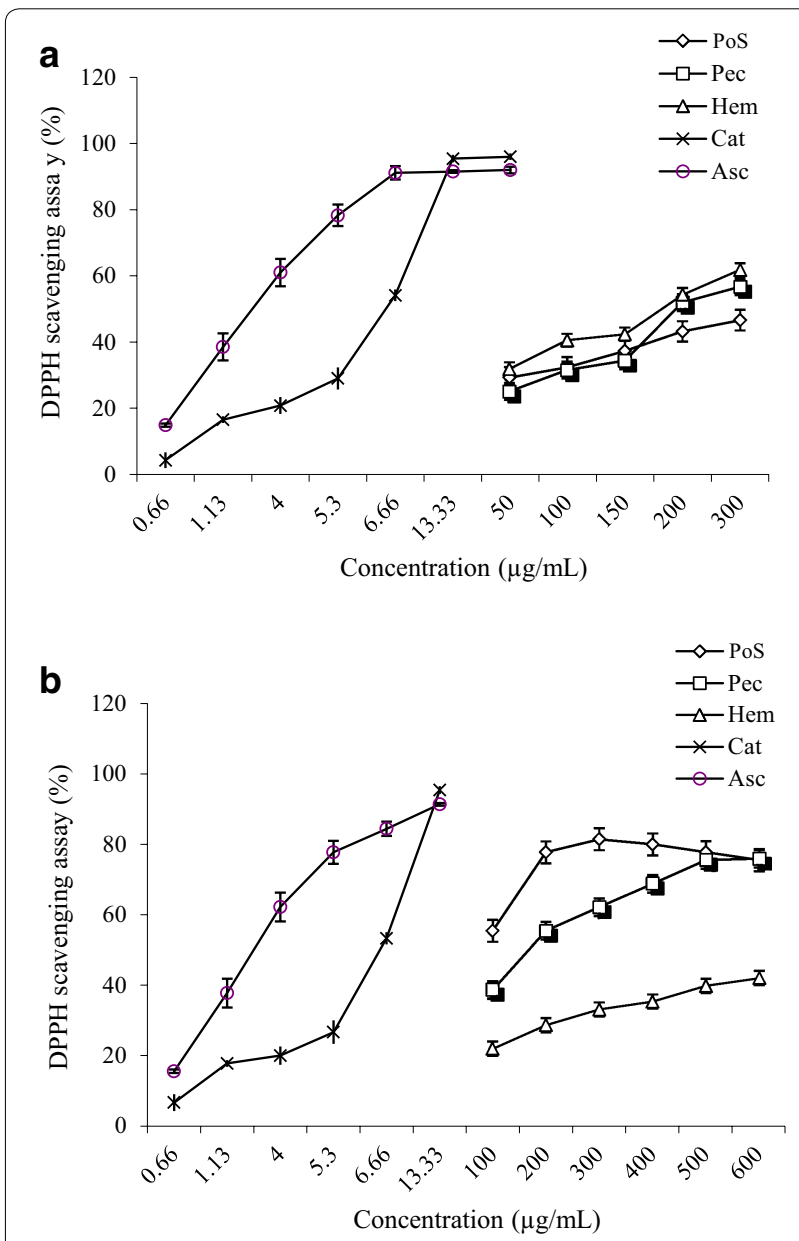

Fig. 6 DPPH-free radical scavenging activity (\%) of polysaccharide isolate from Allanblackia floribunda stem bark (a) and Chromolaena odorata leaves (b). Asc: Ascorbic acid; Cat: Catechin

poor stimulation in the production of INF- $\gamma$ and proliferation of PBMCs (Fig. 9). In this specie, Hem produced significant quantity of spots (Fig. 9). At $200 \mu \mathrm{g} / \mathrm{mL}$, A. floribunda Hem produced more spots $(63 \pm 5)$ than BCG $(41 \pm 2.3$ spots $)$ and $\mathrm{Mal} \mathrm{Ag}(32 \pm 2.8$ spots $)$ at $50 \mu \mathrm{g} /$ $\mathrm{mL}$. In the case of $C$. odorata, the quantity of spots produced in the presence of PoS and Pec increased significantly with the concentration applied. C. odorata PoS produced $60.66 \pm 5$ and $127.33 \pm 9$ at 100 and $200 \mu \mathrm{g} /$ $\mathrm{mL}$ respectively ( $47 \%$ increase) while for C. odorata Pec, the increase was $28 \%, 10.33-35$ spots (Fig. 9).

\section{Discussion}

Complementary and alternative medicines have been used historically around the world to treat many diseases. While the mechanisms of action of many plant products remain to be elucidated, further study in this area is essential for the identification of novel therapeutics with 


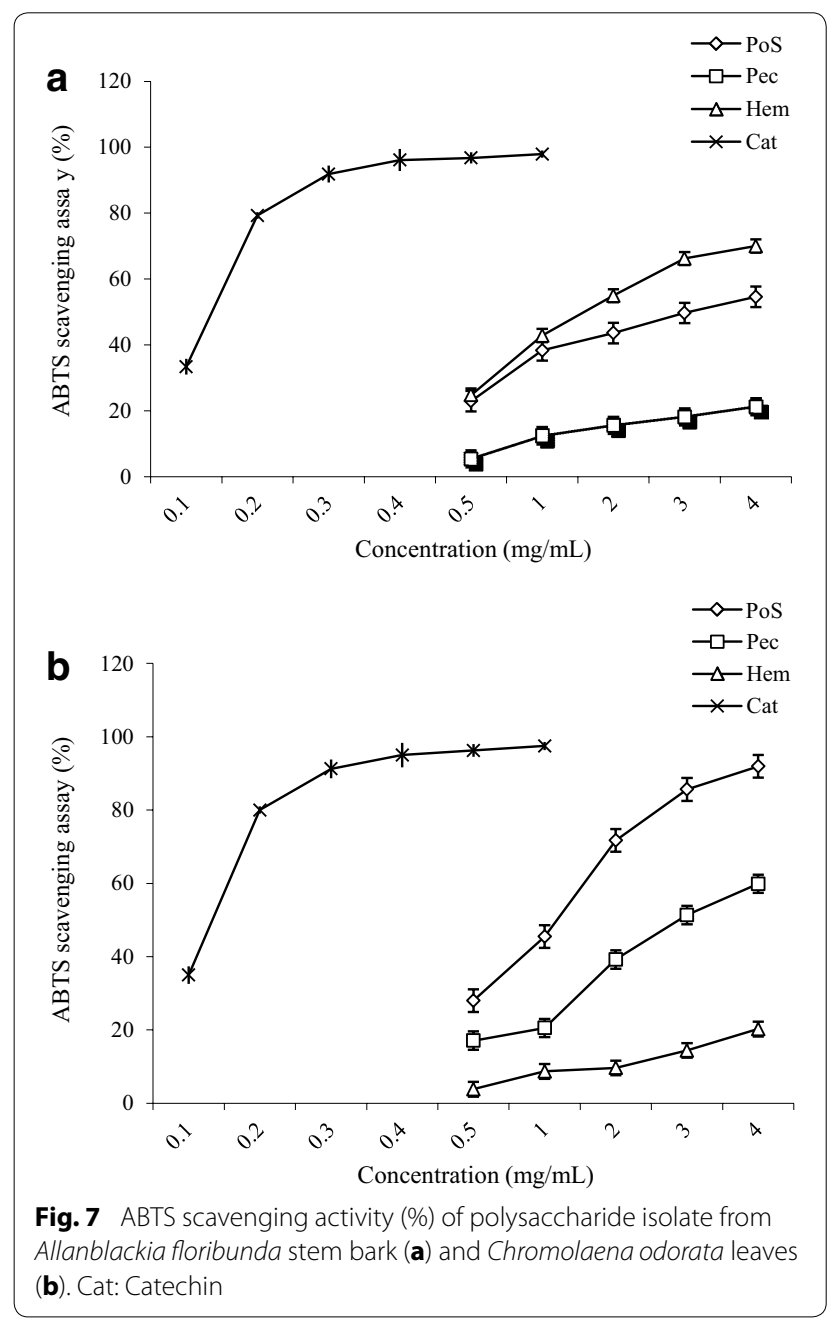

immunomodulatory activity [3]. The characterization of the various fractions by Bradford [20], Folin-Ciocalteu [21], and Dubois et al. [22] methods shows a variability of the different metabolites in plants. The presence of proteins can be justified by the presence of glycoproteins including AGPs. According to Chen et al. [29], the bioactivity of polysaccharides depends primarily on their chemical environment and their combination with other compounds such as proteins, polyphenols and lipids.

Looking at the saccharide composition of the three polysaccharide fractions, it was observed that these extracts had different monosaccharide compositions. In the PoS fractions, Ara and Gal were the major monosaccharides found, supporting the fact that arabinogalactans are the primary macromolecules. Medicinal plants extracts containing AGPs have been shown to stimulate the proliferation and IgM-production in mouse lymphocytes [9, 30]. Pec fractions mostly contained GalA and Gal. The presence of GalA (up to $30 \%$ ) indicated the presence of
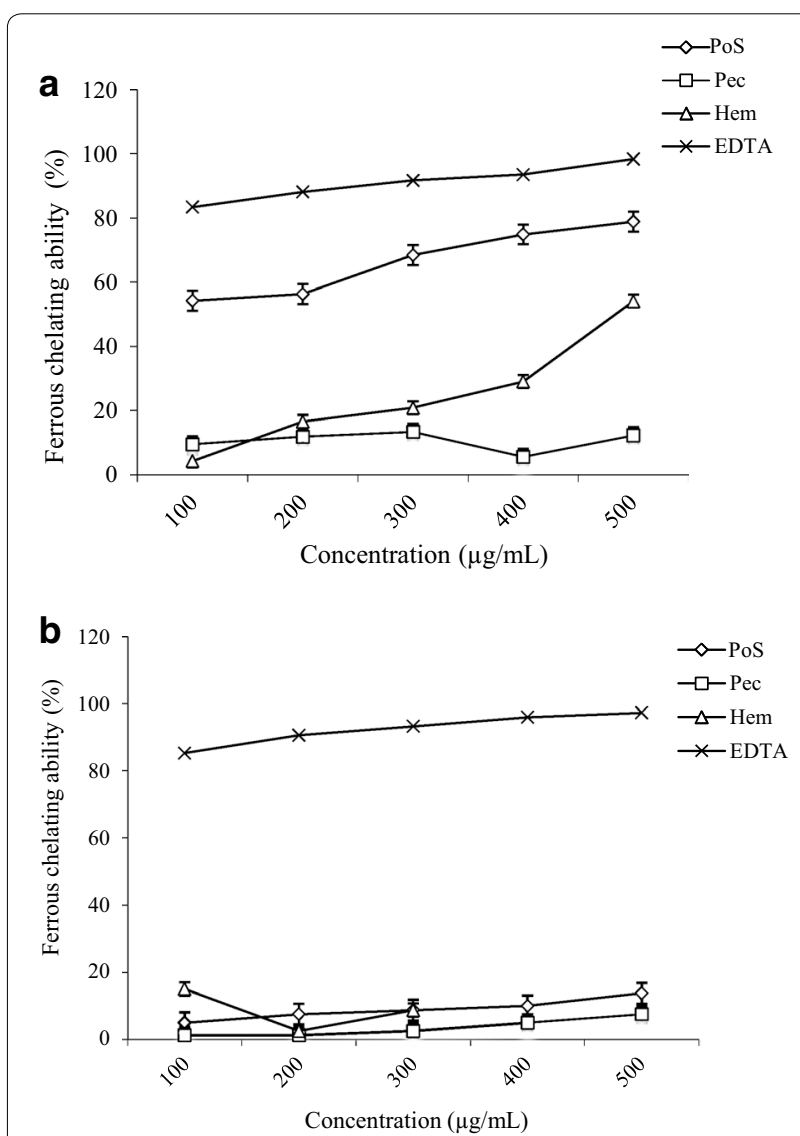

Fig. 8 Ferrous ion chelating capacity (\%) of polysaccharide isolate from Allanblackia floribunda stem bark (a) and Chromolaena odorata leaves $(\mathbf{b})$

soluble pectin, specifically the homogalacturonan polymers. Hem fractions contained predominantly Xyl, GalA and Xyl (upto $80 \%$ ) for A. floribunda and C. odorata respectively.

Natural antioxidants can be considered as potential therapeutic agents against many diseases resulting from oxidative stress such as diabetes, cancer, neurodegenerative and cardiovascular diseases. Four antioxidant assays, namely Ferric reducing antioxidant potential (FRAP), DPPH free radical scavenging activity, ABTS free-radical-scavenging and ferrous ion chelating ability were performed in order to explore the antioxidant potential. The DPPH and ABTS radical scavenging activities were tested to evaluate the ability of the polysaccharide fractions to provide hydrogen to a free radical. A. floribunda Hem and $C$. odorata PoS fractions showed the highest activity (over $60 \%$ at $4 \mathrm{mg} / \mathrm{mL}$ ). This activity could be due to the large amount of phenolic compounds found in these fractions. Polyphenols have been previously identified in the polysaccharide fractions of various plants [31, 32], and it has been reported that polysaccharides are able to bind 


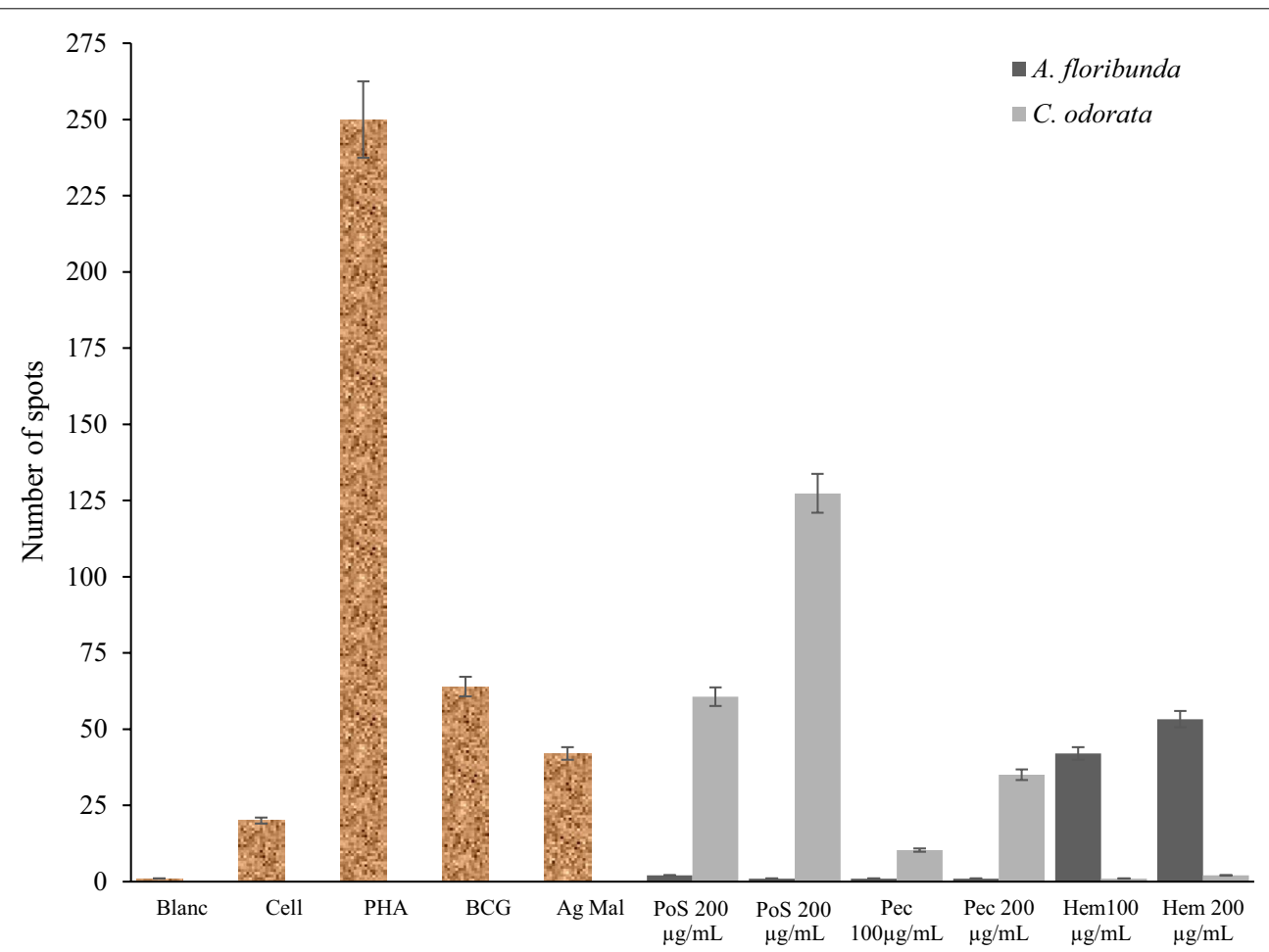

Fig. 9 Effects of polysaccharide fractions on cell proliferation and interferon production by ELISPOT. Mal Ag: malaria antigen

to polyphenols by intermolecular interactions [33]. The presence of polyphenols in polysaccharide fractions is therefore to be considered [8].

The immunostimulatory activity was perfomed through the proliferation of PBMCs and the production of INF- $\gamma$. The result showed that significant activity was observed in the Hem fraction of A. floribunda and PoS fraction of $C$. odorata. These fractions also showed the best DPPH and ABTS radical scavenging activity. For $C$. odorata, the presence of type II arabinogalactan in the PoS fraction could justify these properties [3, 34]. Although, A. floribunda PoS are rich in type II arabinogalactan, this fraction did not show immunomodulatory property. However, the results obtained with Hem of $A$. floribunda are in agreement with those of Zha et al. [35]. These authors showed that, hemicellulose HPS-1B23 isolated from the stems of Dendrobium huoshanense, a plant used in traditional Chinese medicine, stimulates the immune system at different levels [stimulation of interferon gamma (IFN- $\gamma$ ) and the secretion of tumour necrosis alpha factors (TNF- $\alpha)]$.

\section{Conclusion}

In this study, soluble polysaccharides, pectic and soluble hemicellulose fractions were isolated from the dry stem bark of A. floribunda and the leaves of C. odorata used in Cameroonian traditional medicine. An evaluation of their chemical and biological properties showed that $A$. floribunda Hem fraction and C. odorata PoS fraction had significant DPPH and ABTS radical scavenging activities and immunostimulatory activity via stimulation of PBMC and production of IFN- $\gamma$ in a dose-dependent manner. These results may justify the traditional use of these plants. Further research is necessary to have supporting evidence that the antioxidative and immunomodulative activities of these fractions are really connected to the polysaccharides and not polyphenols.

\section{Abbreviations}

AGPs: arabino galactan proteins; PBMCs: peripheral blood mononuclear cells; ELISPOT: enzyme linked immunospot technique; CWM: cell wall material; DPPH: 1,1-diphenyl-2-picryl hydrazyl; ABTS: acide 2,2'-azino-bis-3-éthylbenzylthiazoline-6-sulphonique; RPMI medium: Roswell Park Memorial Institute medium; Dw: dry weight.

\section{Authors' contributions}

TB conceived the project, participated in the analysis of monosaccharide composition and AGP quantification and supervised the work all through, RM participated in carrying out the immunomodulatory test and supervised the work, ALW, CDNT and OK contributed in phenols and proteins quantification, oxidative and immunomodulatory tests, and also revised the manuscript, FMK and JEKN participated in work design and drafted the manuscript. All authors read and approved the final manuscript. 


\section{Author details}

${ }^{1}$ Laboratory of Phytoprotection and Valorisation of Plants Resources, Biotechnology Centre-Nkolbisson, P.O. Box 3851, Messa, Yaounde, Cameroon. ${ }^{2}$ Department of Biochemistry, Faculty of Science, University of Yaounde I, P.O. Box 812, Yaounde, Cameroon. ${ }^{3}$ Department of Animal Biology and Physiology, Faculty of Science, University of Yaounde I, P.O. Box 812, Yaounde, Cameroon.

\section{Acknowledgements}

The authors acknowledge the institutional and material support from the Biotechnology Centre of the University of Yaounde 1. Special thanks to the Laboratory of Glycobiology and Extracellular Matrix of plants (Glyco-MEV) of University of Rouen for the excellent technical assistance. We are grateful to Dr Achu Mercy Bih Loh (Department of Biochemistry, University of Yaounde 1, Cameroon) for improving the English text.

\section{Competing interests}

The authors declare that they have no competing interests.

Received: 23 January 2015 Accepted: 17 November 2015

Published online: 09 December 2015

\section{References}

1. Aboughe-Angone S, Nguema-Ona E, Boudjeko T, Driouich A. Plant cell wall polysaccharides as immmunomodulators of the immune system. Cur Top Phytochem. 2011;10:1-16

2. Wasser SP. Medicinal mushrooms as a source of antitumor and immunomodulating polysaccharides. Appl Microbiol Biotechnol. 2002;60:258-74

3. Kouakou K, Schepetkin IA, Yapi A, Kirpotina LN, Jutila MA, Quinn MT. Immunomodulatory activity of polysaccharides isolated from Alchornea cordifolia. J Ethnopharmacol. 2013;146(1):232-42.

4. Thangam R, Sathuvan M, Poongodi A, Sureshe V, Pazhanichamy K, Sivasubramanian S, Kanipandian N, Ganesan N, Rengasamy R, Thirumurugan R, Kannan S. Activation of intrinsic apoptotic signaling pathway in cancer cells by Cymbopogon citratus polysaccharide fractions. Carbohydr Polym. 2014;107:138-50

5. Yang X, Wang R, Zhang S, Zhu W, Tang J, Liu J, Chen P, Zhang D, Yea W, Zheng Y. Polysaccharides from Panax japonicus C.A. Meyer and their antioxidant activities. Carbohydr Polym. 2014;101:386-91.

6. Wang Z, Luo D. Antioxidant activities of different fractions of polysaccharide purified from Gymnostemma pentaphyllum Makino. Carbohydr Polym. 2006;68:54-8.

7. Yamaguchi R, Tatsumi MA, Karo K, Yoshimitsu U. Effect of metal salts and fructose on the autoxidation of methyl linoleate in emulsions. Agricultural Biol Chem. 1988;52:849-50.

8. Mediesse-Kengne F, Woguia AL, Fogue P, Atogho-Tiedeu B, Simo G, Boudjeko T. Antioxidant properties of cell wall polysaccharides of Stevia rebaudiana leaves. J Cost Lif Med. 2014;2(12):962-9.

9. Diallo D, Paulsen BS, Liljeback TH, Michaelsen TE. Polysaccharides from the roots of Entada Africana Guill. et Perr., Mimosaceae, with complement fixing activity. J Ethnopharm. 2001;74:159-71.

10. Togola A, Inngjerdingen M, Diallo D, Barsett H, Rolstad B, Michaelsen TE, Paulsen BS. Polysaccharides with complement fixing and macrophage stimulation activity from Opilia celtidifolia, isolation and partial characterization. J Ethnopharm. 2007;115:423-31.

11. Wagner H, Willer F, Samtleben R, Boos G. Search for the antiprostatic principle of stinging nettle (Urtica dioica) roots. Phytomedicine. 1994;1:213-4.

12. Bilanda DC, Dimo T, Dzeufiet DPD, Bella NMT, Oumarou BF, Nguelefack TB, Kamtchouing P. Antihypertensive and antioxidant effects of Allanblackia floribunda Oliv. (Clusiaceae) aqueous extract effects in alcohol and sucrose-induced hypertension in rats. J Ethnopharmacol. 2010;128:634-40.

13. Boudjeko T, Kanemoto NJE, Woguia AL, Njintang YN. Partial characterization, antioxidative properties and hypolipidemic effects of oilseed cake of Allanblackia floribunda and Jatropha curcas. BMC Compl Alter Med. 2013:13:352.

14. Nagem TJ, de Oliveira F, Peres V. Tetraoxygenated naturally occurring xanthones. Phytochemistry. 2000;55:683-710.
15. N'guessan K, Kadja B, Zirihi GN, Traoré D, Aké-Assi L. Screening phytochimique de quelques plantes médicinales ivoiriennes utilisées en pays Krobou (Agboville, Côte-d'Ivoire). Sci Nat. 2009;6:1-15.

16. Owoyele BV, Oguntoye SO, Ogunbiyi BA, Aruboula EA, Soladoye AO. Analgesic, anti-inflammatory and antipyretic activities from flavonoid fractions of Chromolaena odorata. J Med PI Res. 2008;2(9):2019-25.

17. Phan TT, See P, Lee ST, Chan SY. Anti-oxidant effects of the extracts from the leaves of Chromolaena odorata on human dermal fibroblasts and epidermal keratinocytes against hydrogen peroxide and hypoxanthine oxidase induced damage. Burns. 2001;27:319-27.

18. Schultz C, Johnson K, Currie G, Bacic A. The classical arabinogalactanprotein gene family of arabidopsis. Plant Cell. 2000;12:1751-67.

19. Ray B, Loutier-Bourhis C, Condamine E, Driouich A, Lerouge P. Structural investigation of hemicellulosic polysaccharides from Argania spinosa: characterization of novel xyloglucan motif. Carbohydr Res. 2004;339:201-8

20. Bradford MM. A rapid and sensitive method for the quantification of microgram quantities of protein utilizing the principles of protein dye binding. Anal Chem. 1976;72:248-54

21. Nguimbou RM, Boujeko T, Njintang YN, Makhlouf H, Mbofung CMF, Scher J. Mucilage chemical profile and antioxidant properties of giant swamp taro tubers. J Food Sci Technol. 2012;. doi:10.1007/s13197-012-0906-6.

22. Dubois M, Gilles KA, Hamiltion JK, Rebers PA, Smith F. Colorimetric method for determination of sugars and related substances. Anal Chem. 1956;28:350-6.

23. York WS, Darvill AG, McNeil M, Stevenson TT, Albersheim P. Methods in enzimology, vol. 3. 118th ed. San Diego: Academic Press; 1985.

24. Boudjeko T, Rihouey C, Omokolo ND, El Hadrami I, Lerouge P, Driouich A. Characterisation of cell wall polysaccharides, arabinogalactans-proteins (AGPs) and phenolics of Cola nitida, Cola acuminata and Garcinia kola seeds. Carbohydr Polym. 2009:78:820-7.

25. Re S, Bui HH, Wang R. Quantitative structure-activity relationship analysis of phenolic antioxidants. Free Radic Biol Med. 1999:26:285-94.

26. Dinis TCP, Madeira VMC, Almeida LM. Action of phenolic derivates (acetoaminophen, salycilate, and 5-aminosalycilate) as inhibitors of membrane lipid peroxidation and peroxyl radicals scavengers metal chelating activities: inhibition of the complexes ferrozine-ferrous irons. Arch Biochem Biophys. 1994;315:161-9.

27. Chi DS, Harris NS. Enhancement of human amniotic cell growth by FicollPlaque blood lymphocytes. Immunol Meth. 1978;19:169-72.

28. Cserkinsky CC, Nilsson L, Tarkawki A, Ouchterlony O, Jeansson S, Gretzer C. An immunoenzyme procedure for enumerating fibronectin-secreting cells. J Immunoassay. 1984;5:291-302.

29. Chen $H$, Zhang M, Qu Z, Xie B. Antioxidant activities of different fractions of polysaccharide conjugates from green tea (Camellia sinensis). Food Chem. 2008;106:559-63.

30. Classen B, Thude S, Blaschek W, Wack M, Bodinet C. Immunomodulatory effects of arabinogalactan-proteins from Baptisia and Echinacea. Phytomedicine. 2006;13:688-94

31. Smiderle FR, Ruthes AC, Van AJ, Chanput W, lacomini M, Wichers HJ, Van Griensven LJ. Polysaccharides from Agaricus bisporus and Agaricus brasiliensis show similarities in their structures and their immunomodulatory effects on human monocytic THP-1 cells. BMC Compl Altern Med. 2011; doi:10.1186/1472-6882-11-58.

32. Skyberg JA, Rollins MF, Holderness JS, Marlenee NL, Schepetkin IA Goodyear A, Dow SW, Jutila MA, Pascual DW. Nasal Acai polysaccharides potentiate innate immunity to protect against pulmonary Francisella tularensis and Burkholderia pseudomallei infections. PLoS Pathog. 2012; doi:10.1371/journal.ppat.1002587.

33. Renard CM, Baron A, Guyot S, Drilleau JF. Interactions between apple cell walls and native apple polyphenols: quantification and some consequences. Int J Biol Macromol. 2001;29(2):115-25.

34. Yamada $H$, Kiyohara $H$. Structure of the neutral carbohydrate side-chains in anti-complementary acidic polysaccharides from the root of Angelica acutiloba Kitagawa. Carbohydr Res. 1999;187:255-65.

35. Zha XQ, Luo JP, Luo SZ, Jiang ST. Structure identification of a new immunostimulating polysaccharide from the stems of Dendrobium huoshanense. Carbohydr Polym. 2007;69:86-93. 